\title{
Changes of Sleep Disordered Breathing and Quality of Life after Adenotonsillectomy in Pediatric Obstructive Sleep Apnea
}

\author{
Sang Woo Seon ${ }^{1}$, Jae Hyun Jung ${ }^{1}$, Sang Kuk Lee ${ }^{1}$, Se A Lee ${ }^{1}$, Eunsang Lee ${ }^{1}$, \\ Seungjae Lee ${ }^{1}$, Seung Hoon Lee ${ }^{2}$, Jae Yong Lee ${ }^{1}$, and Ji Ho Choi ${ }^{1}$ \\ ${ }^{1}$ Department of Otorhinolaryngology-Head and Neck Surgery, Bucheon Hospital, Soonchunhyang University College of Medicine, \\ Bucheon; and ${ }^{2}$ Department of Otorhinolaryngology-Head and Neck Surgery, Ansan Hospital, Korea University College of Medicine, \\ Ansan, Korea
}

\section{소아 폐쇄성수면무호흡증에서 편도 및 아데노이드 절제술 후 수면호흡장애 및 삶의 질의 변화}

선상우 ${ }^{1} \cdot$ 정재현 $^{1} \cdot$ 이상국 ${ }^{1} \cdot$ 이세아 $^{1} \cdot$ 이은상 $^{1} \cdot$ 이승재 $^{1} \cdot$ 이승훈 $^{2} \cdot$ 이재용 $^{1} \cdot$ 최지호 $^{1}$ 순천향대학교 의과대학 부천병원 이비인후-두경부외과학교실, ${ }^{1}$ 고려대학교 의과대학 안산병원 이비인후-두경부외과학교실 ${ }^{2}$

Received September 22, 2016

Revised November 17, 2016 Accepted November 28, 2016 Address for correspondence Ji Ho Choi, MD, PhD Department of OtorhinolaryngologyHead and Neck Surgery, Bucheon Hospital,

Soonchunhyang University College of Medicine,

170 Jomaru-ro, Bucheon 14584 Korea

Tel $+82-32-621-5015$

Fax $+82-32-621-5016$

E-mail handsomemd@hanmail.net
Background and Objectives Pediatric obstructive sleep apnea (OSA) can have an effect on the quality of life (QOL) such as behavior, school performance, emotional distress and daytime function. We aim to verify changes in sleep disordered breathing based on polysomnographic findings and disease specific health related QOL before and after adenotonsillectomy in Korean children with OSA.

Subjects and Method A total 20 children aged 3 through 13 years old (mean age $=6.7$ years old and male/female $=14 / 6$ ) with OSA were included. We evaluated respiratory disturbances in patients using the standard polysomnography and the OSA-specific health related QOL based on Korean Obstructive Sleep Apnea-18 Survey (KOSA-18).

Results There were significant improvements in apnea-hypopnea index (from $9.4 \pm 7.4$ to $1.1 \pm 0.8$ events/hour, $p<0.001)$ and total score of KOSA-18 (71.3 \pm 26.0 to $33.6 \pm 10.7, p<0.001)$ after adenotonsillectomy.

Conclusion Sleep disordered breathing and QOL improve significantly after adenotonsillectomy in Korean OSA children.

Korean J Otorhinolaryngol-Head Neck Surg 2017;60(4):174-8

Key Words Adenoidectomy · Child · Obstructive sleep apnea · Quality of life · Tonsillectomy.

\section{서 론}

자는 동안 상기도의 부분 또는 완전 폐쇄가 빈번하게 나타 나는 것을 특징으로 하는 폐쇄성수면무호흡증(obstructive sleep apnea, OSA)은 소아 인구에서 대략 1 3\% 정도 나타나

This is an Open Access article distributed under the terms of the Creative Commons Attribution Non-Commercial License (http://creativecommons.org/licenses/by-nc/4.0) which permits unrestricted non-commercial use, distribution, and reproduction in any medium, provided the original work is properly cited.
는 것으로 알려져 있다. ${ }^{1-4)}$ 소아 폐쇄성수면무호흡증의 주요 한 원인은 편도 및 아데노이드 비대로 일반적으로 상기도 근 골격계의 성장 속도에 비해 2 8세 사이에 편도, 아데노이드 같 은 임파선 조직의 성장 속도가 상대적으로 더 빨라 상기도가 많이 좁아지기 때문이다. ${ }^{1,2)}$ 진단은 병력, 신체검사, 수면다원 검사를 통해 이루어지는데, 병력에서는 코골이, 수면 중 무호 흡, 잦은 뒤척임, 구강호흡 또는 코막힘 등을 포함하는 다양 한 증상들을 확인할 수 있다. ${ }^{5)}$ 또한, 신체검사에서는 비강, 
구강, 인두, 후두 등 상기도에 구조적인 문제가 있는지 또는 비만 관련 이상 소견이 있는지 평가해야 하며, 수면다원검사 에서는 수면 1 시간당 1 회 이상의 폐쇄성 무호흡, 저호흡 등 과 같은 수면호흡장애가 있는지 또는 폐쇄성 저환기(obstructive hypoventilation) 소견이 있는지 확인하는 것이 중요하 다. ${ }^{1,25)}$ 만약 소아에서 폐쇄성수면무호흡증이 진단 및 치료되 지 않고 지속되게 된다면 성장 장애, 심혈관계 질환, 학습 및 행동 장애 등 심각한 합병증 발생 가능성이 높아지게 된다.1,2,6 그러므로, 수면 중 호흡장애가 의심되는 경우에는 정확한 진 단과 적절한 치료가 신속하게 이루어져야 한다.

소아에서 폐쇄성수면무호흡증이 신속하게 치료되어야 하 는 또 다른 중요한 이유는 바로 폐쇄성수면무호흡증이 삶의 질에 많은 영향을 미친다는 사실이다. ${ }^{7)}$ 현재 소아 폐쇄성수면 무호흡증 환자들을 대상으로 삶의 질을 알아본 연구들은 주 로 설문조사를 통해 시행되는데, 소아 폐쇄성수면무호흡증에 특화된 삶의 질을 평가하기 위해 만들어진 OSA-18 Survey (OSA-18)라는 설문이 국외에서 개발되면서부터 관련 연구 들이 활성화되었으며, 이후 OSA-18의 한국어 버전인 Korean Obstructive Sleep Apnea-18 Survey(KOSA-18)를 사용한 국 내 연구들도 시행되기 시작하였다. ${ }^{7-12)}$ 하지만, 아직까지 폐쇄성 수면무호흡증이 있는 국내 소아 환자들을 대상으로 수술 전 후 수면다원검사 결과와 함께 삶의 질을 비교한 연구는 찾아 볼 수 없었다. 따라서, 본 연구의 목적은 한국인 소아 폐쇄성 수면무호흡증 환자들을 대상으로 1) 편도 및 아데노이드 절제 술 전후의 수면다원검사 결과와 KOSA-18 설문에 기초한 삶 의 질을 비교하는 것이며, 2) 편도 및 아데노이드 절제술 전후 폐쇄성수면무호흡증이 삶의 질에 미치는 영향 및 폐쇄성수 면무호흡증의 심각도에 따른 삶의 질을 비교하는 것이다.

\section{대상 및 방법}

\section{대 상}

코골이, 수면 중 무호흡, 구강호흡 등과 같은 수면호흡장애 관련 증상들을 주소로 내원한 소아들 중 신체검사상 편도 크 기가 3,4 단계(양측 편도 사이의 거리가 양측 전구개궁사이의 거리에 비하여 $1 / 2$ 이상 좁아져 있는 경우) 및 측면 방사선학 적 검사 소견상 아데노이드 비대로 인해 후비강이 $50 \%$ 이상 좁아져 있으면서 수면다원검사 결과 폐쇄성수면무호흡증으 로 진단받은 3 13세 환자들을 대상으로 하였다. 두개 안면 기 형, 신경이나 근육 이상, 행동 장애 등을 포함하여 연구에 부 적합할 것으로 판단된 경우들은 제외하였다. 수술 전 1차 수 면다원검사 및 설문조사, 편도 및 아데노이드 절제술, 수술 3 개월 후 2 차 수면다원검사 및 설문조사를 완료한 총 20 명의
소아 환자가 최종적으로 연구 대상자로 포함되었으며, 남자는 14 명, 여자 6명이었고, 평균 연령은 6.7세였다. 본 연구는 고려 대학교 안산병원 임상시험심사위원회(Institutional Review Board, IRB No. AS0783-002)의 승인 후 진행되었다.

\section{수면다원검사}

수술 전후 대상자들의 수면 중 뇌파, 안전도, 근전도, 근긴 장도, 심전도, 호흡 기류 및 노력, 산소포화도, 코골이, 체위 등 다양한 생체신호를 기록하여 수면 상태 및 질환을 확인하기 위해 표준 수면다원검사 장비(Alice 4; Respironics, Atlanta, GA, USA)를 사용하였다. 총 수면시간(total sleep time), 수면 효율(sleep efficiency), 각성 지수(arousal index) 등 수면의 질 관련 지표들(sleep parameters), 1 3단계 비렘수면, 렘수면 등 수면 구조 관련 지표들(sleep architecture parameters), 무호 흡-저호흡 지수(apnea-hypopnea index, AHI), 최저 산소 포화도(minimum oxygen saturation), 코골이 등 수면호흡장 애 지표(sleep disordered breathing parameters) 등을 조사 하였다.

\section{설문조사}

폐쇄성수면무호흡증이 있는 소아 환자의 삶의 질을 확인하 기 위해 보호자에게 수술 전후 설문조사를 시행하였다. 설문 조사는 소아 폐쇄성수면무호흡증에 특화된 삶의 질을 평가하 기 위해 만들어진 OSA-18의 한국어 버전인 KOSA-18을 이 용하였다. ${ }^{710)} \mathrm{KOSA}-18$ 은 수면 상태(sleep disturbance, 4가지 설문), 신체적 증상(physical suffering, 4가지 설문), 정서적 증 상(emotional distress, 3 가지 설문), 낮시간의 생활(daytime problems, 3 가지 설문), 보호자 상태(caregiver concerns, 4 가 지 설문) 등 5 가지 항목, 총 18 가지 설문으로 구성되어 있다. 각 설문에 대해 1점(전혀 없다)부터 7점(항상 있다)까지 해당하 는 점수를 배점할 수 있어 총점이 18점에서 126점까지 나타 날 수 있다. 또한, 점수에 따라서 폐쇄성수면무호흡증이 삶의 질에 미치는 정도를 구분하였는데, 총점 60점 미만은 삶의 질에 적은 영향(small impact)을 미치는 경우로, 총점 60 점 이 상 80점 미만은 중간 영향(moderate impact)을 미치는 경우로, 총점 80점 이상은 큰 영향(large impact)을 미치는 경우로 정 의하였다. ${ }^{13)}$

\section{통계적 분석}

수술 전후 수면다원검사와 삶의 질(KOSA-18) 비교에는 Wilcoxon's Signed Ranks test를 이용하였다. 통계 프로그 램은 SPSS(SPSS ver. 10.0; SPSS Inc., Chicago, IL, USA)를 사용하였으며, 통계학적으로 유의한 것으로 판단하는 기준은 
$p<0.05$ 인 경우로 하였다.

\section{결 과}

\section{수술 전후 수면다원검사 비교}

폐쇄성수면무호흡증이 있는 소아에서 편도 및 아데노이드 절제술 전후의 수면다원검사 결과 비교는 Table 1에 정리되 어 있다. 수술 후 수면의 질 관련 지표들(sleep parameters) 중 총 수면시간, 수면 효율에서는 유의한 변화가 없었으나 각성 지 수(술 전 17.9 \pm 5.8 , 술 후 9.8 $\pm 4.4, p<0.001$ )에서는 통계적으로 유의한 개선이 있었다. 수술 후 모든 수면 구조 관련 지표들 (sleep architecture parameters)에서는 유의한 변화가 없었으나 무호흡-저호흡 지수(술 전 9.4 \pm 7.4 , 술 후 $1.1 \pm 0.8, p<0.001$ ), 최저 산소포화도(술 전 $83.7 \pm 13.4$, 술 후 90.8 $\pm 3.8, p=0.024$ ) 등 을 포함한 모든 수면호흡장애 지표(sleep disordered breathing parameters)들에서는 통계적으로 유의한 호전이 있었다.
수술 전후 삶의 질(Korean Obstructive Sleep Apnea-18 Survey) 비교

폐쇄성수면무호흡증이 있는 소아에서 편도 및 아데노이드 절제술 전후 KOSA-18 설문에 기초한 삶의 질 비교는 Table 2에 나타나 있다. 수술 후 수면 상태(술 전 17.2 \pm 6.4 , 술 후

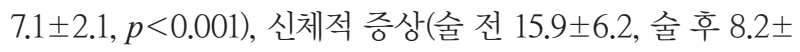
$3.7, p<0.001$ ), 정서적 증상(술 전 $11.3 \pm 6.0$, 술 후 5.9 \pm 3.1 ,

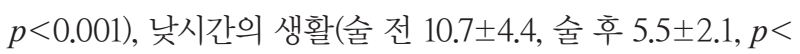
0.001 ), 보호자 상태(술 전 $16.3 \pm 7.0$, 술 후 $6.9 \pm 2.2, p<0.001$ ) 등 5 가지 항목과 이를 모두 합한 총점(술 전 71.3 \pm 26.0 , 술 후 33.6 $\pm 10.7, p<0.001)$ 모두에서 통계적으로 유의한 호전이 있었다.

\section{수술 전후 폐쇄성수면무호흡증이 삶의 질에 미치는 영향} 비교

폐쇄성수면무호흡증이 있는 소아에서 편도 및 아데노이드 절제술 전후 폐쇄성수면무호흡증이 삶의 질에 미치는 영향 비교는 Table 3에 요약되어 있다. 삶의 질에 적은 영향(small

Table 1. Changes of polysomnographic findings in children with obstructive sleep apnea before and after adenotonsillectomy ( $n=20)$

\begin{tabular}{|c|c|c|c|}
\hline Polysomographic parameters & Preoperative & Postoperative & p-value* \\
\hline \multicolumn{4}{|l|}{ Sleep quality parameters } \\
\hline TST, min & $440.0 \pm 38.6$ & $440.9 \pm 32.6$ & 0.681 \\
\hline Sleep efficiency, \% & $91.5 \pm 5.3$ & $92.5 \pm 5.7$ & 0.204 \\
\hline Arousal index, events/hour of TST & $17.9 \pm 5.8$ & $9.8 \pm 4.4$ & $<0.001$ \\
\hline \multicolumn{4}{|c|}{ Sleep architecture parameters (sleep-stage duration, as \% of TST) } \\
\hline Stage N1 & $9.3 \pm 4.7$ & $7.9 \pm 7.0$ & 0.390 \\
\hline Stage N2 & $44.7 \pm 6.6$ & $45.5 \pm 8.3$ & 0.370 \\
\hline Stage N3 (slow-wave sleep) & $27.6 \pm 7.5$ & $27.9 \pm 9.9$ & 0.794 \\
\hline Stage R (REM sleep) & $17.5 \pm 4.0$ & $18.5 \pm 4.6$ & 0.546 \\
\hline \multicolumn{4}{|l|}{ Sleep disordered breathing parameters } \\
\hline AHI, events/hour of TST & $9.4 \pm 7.4$ & $1.1 \pm 0.8$ & $<0.001$ \\
\hline Obstructive AHI, events/hour of TST & $8.2 \pm 6.8$ & $0.4 \pm 0.6$ & $<0.001$ \\
\hline Apnea index, events/hour of TST & $4.3 \pm 4.9$ & $0.7 \pm 0.6$ & 0.008 \\
\hline Min $\mathrm{SaO}_{2}, \%$ & $83.7 \pm 13.4$ & $90.8 \pm 3.8$ & 0.024 \\
\hline Snoring, \% & $19.7 \pm 19.0$ & $8.2 \pm 18.0$ & 0.007 \\
\hline
\end{tabular}

Data are presented as mean \pm SD. *Wilcoxon's Signed Ranks test. TST: total sleep time, N: Non-REM, R: REM, AHI: apnea-hypopnea index, Min $\mathrm{SaO}_{2}$ : minimum oxygen saturation, REM: ropid eye movement

Table 2. Changes of the OSA-18 survey in children with OSA before and after adenotonsillectomy $(n=20)$

\begin{tabular}{lccc}
\hline \multicolumn{1}{c}{ OSA-18 domain (item) } & Preoperative mean score & Postoperative mean score & p-value* \\
\hline Sleep disturbance (4) & $17.2 \pm 6.4$ & $7.1 \pm 2.1$ & $<0.001$ \\
Physical suffering (4) & $15.9 \pm 6.2$ & $8.2 \pm 3.7$ & $<0.001$ \\
Emotional distress (3) & $11.3 \pm 6.0$ & $5.9 \pm 3.1$ & $<0.001$ \\
Daytime problems (3) & $10.7 \pm 4.4$ & $5.5 \pm 2.1$ & $<0.001$ \\
Caregiver concerns (4) & $16.3 \pm 7.0$ & $6.9 \pm 2.2$ & $<0.001$ \\
Mean total score (18) & $71.3 \pm 26.0$ & $33.6 \pm 10.7$ & $<0.001$ \\
\hline
\end{tabular}

Data are presented as mean \pm SD. *Wilcoxon's Signed Ranks test. OSA: obstructive sleep apnea 
Postoperative Changes of SDB and QOL in Pediatric OSA I Seon SW, et al.

Table 3. Impact of pediatric OSA on QOL (KOSA-18) before and after adenotonsillectomy $(n=20)$

\begin{tabular}{lcc}
\hline \multicolumn{1}{c}{ Degree of impact } & \multicolumn{2}{c}{ Number (\%) of children } \\
\cline { 2 - 3 } & Preoperative & Postoperative \\
\hline Small impact (total score $<60)$ & $9(45)$ & $20(100)$ \\
Moderate impact $(60 \leq$ total score $<80)$ & $4(20)$ & $0(0)$ \\
Large impact (total score $\geq 80)$ & $7(35)$ & $0(0)$ \\
\hline
\end{tabular}

Data are presented as mean \pm SD. OSA: obstructive sleep apnea, QOL: quality of life, KOSA-18: Korean Obstructive Sleep Apnea-18 Survey

Table 4. Relationship between severity of pediatric OSA and QOL (KOSA-18) before and after adenotonsillectomy $(n=20)$

\begin{tabular}{|c|c|c|c|c|c|}
\hline \multirow{2}{*}{ Severity of OSA } & \multirow{2}{*}{$\begin{array}{l}\text { Number (\%) } \\
\text { of children }\end{array}$} & \multicolumn{2}{|c|}{ Preoperative } & \multicolumn{2}{|c|}{ Postoperative } \\
\hline & & Mean $\mathrm{AHI}$ & Mean total score & Mean AHI & Mean total score \\
\hline Mild $(1 \leq \mathrm{AHI}<5)$ & $6(30)$ & $3.0 \pm 0.8$ & $59.2 \pm 18.3$ & $1.2 \pm 0.8$ & $35.7 \pm 13.1$ \\
\hline Moderate $(5 \leq \mathrm{AHI}<10)$ & $8(40)$ & $7.3 \pm 1.8$ & $68.1 \pm 22.7$ & $1.1 \pm 0.8$ & $32.4 \pm 9.2$ \\
\hline Severe $(10 \leq \mathrm{AHI})$ & $6(30)$ & $19.0 \pm 6.8$ & $87.5 \pm 31.8$ & $0.9 \pm 1.0$ & $33.0 \pm 11.5$ \\
\hline
\end{tabular}

Data are presented as mean \pm SD. OSA: obstructive sleep apnea, QOL: quality of life, AHI: apnea-hypopnea index, KOSA-18: Korean Obstructive Sleep Apnea-18 Survey

impact)을 미치는 경우(총점 60점 미만)는 수술 전 9명(45\%) 에서 수술 후 20명(100\%)으로, 중간 영향(moderate impact) 을 미치는 경우(총점 60점 이상 80점 미만)는 수술 전 4명(20\%) 에서 수술 후 0 명으로, 큰 영향(large impact)을 미치는 경우 (총점 80점 이상)는 수술 전 7명(35\%)에서 수술 후 0명으로 나타났다.

\section{수술 전후 폐쇄성수면무호흡증의 심각도에 따른 삶의 질 비교}

폐쇄성수면무호흡증이 있는 소아에서 편도 및 아데노이드 절제술 전후 폐쇄성수면무호흡증의 심각도에 따른 삶의 질 비교는 Table 4에 제시되어 있다. 경도(무호흡-저호흡 지수가 1 이상 5 미만, mild) 폐쇄성수면무호흡증의 경우는 6명(30\%) 이었으며, KOSA-18 설문 총점은 수술 전 $59.2 \pm 18.3$ 에서 수 술 후 35.7 \pm 13.1 로 감소하였다. 중등도(무호흡-저호흡 지수 가 5 이상 10 미만, moderate) 폐쇄성수면무호흡증의 경우는 8명(40\%)이었으며, KOSA-18 설문 총점은 수술 전 $68.1 \pm 22.7$

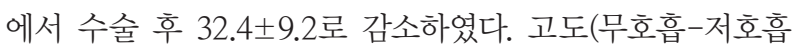
지수가 10 이상, severe) 폐쇄성수면무호흡증의 경우는 6명 (30\%)이었으며, KOSA-18 설문 총점은 수술 전 87.5 \pm 31.8 에 서 수술 후 $33.0 \pm 11.5$ 로 감소하였다.

\section{고 찰}

한국인 소아 폐쇄성수면무호흡증 환자들을 대상으로 편도 및 아데노이드 절제술 전후 수면다원검사 결과 및 KOSA-18 설문에 기초한 삶의 질을 비교한 이번 연구를 통해 저자들은 술 후 수면호흡장애의 명확한 개선과 함께 삶의 질이 유의하
게 호전되는 것을 확인할 수 있었다. 또한, 폐쇄성수면무호흡 증이 삶의 질에 미치는 영향이 술 후 많이 감소한다는 것과 술 후 폐쇄성수면무호흡증의 심각도와 상관없이 삶의 질이 많이 호전된다는 것을 확인할 수 있었다.

Franco 등근 폐쇄성수면무호흡증이 있는 소아 환자들에 서 삶의 질을 평가할 수 있는 설문지를 만들고자 20가지의 설문을 만들어 61 명의 소아 환자들을 대상으로 그 신뢰성과 타당성을 조사하였다. 20 가지 설문 중 부적합한 2가지 설문 은 제외되어 최종적으로 5 가지 항목, 18 가지의 설문으로 구성 된 OSA-18이 개발되었다. 이후 국내에서도 소아 폐쇄성수면무 호흡증 환자들을 대상으로 OSA-18의 한국어 버전인 KOSA18 을 이용하여 삶의 질을 평가하는 여러 연구들이 발표되었 다. ${ }^{10-12)} \mathrm{Choi}$ 등 ${ }^{10)}$ 은 수면호흡장애가 의심되는 소아에서 삶의 질 저하와 인성 및 행동 장애와의 관련성을 확인하기 위해 삶 의 질 관련 설문(KOSA-18, KOSA-6)과 행동 및 인성 장애 관 련 설문(Korean Child Behavior Checklist, Korean Personality Inventory for Children)과의 상관관계를 조사하였다. 그 결과 각 설문 간에 통계학적으로 유의한 상관관계가 있었 으며, 삶의 질이 저하될수록 행동 및 인성 장애가 심해지는 것을 확인할 수 있었다. $\operatorname{Lim}$ 등믄 폐쇄성수면무호흡증으 로 진단받은 소아 환자들을 대상으로 삶의 질(KOSA-18 총 점)과 수면다원검사 지표들[호흡장애지수(respiratory disturbance index), 각성 지수, 코골이, 무호흡 지수, 깊은 수면, 렘 수면, 평균 및 최저 산소포화도, 수면 효율 등과의 연관성을 알아본 결과 삶의 질과 호흡장애지수, 각성 지수, 코골이 등 이 통계적으로 유의한 상관관계가 있는 것으로 나타났다. Cho 등 ${ }^{12)}$ 은 편도 및 아데노이드 비대로 인해 수면호흡장애가 발 생한 소아들을 대상으로 편도 및 아데노이드 절제술 전후 
KOSA-18을 이용하여 삶의 질을 비교하였다. 술 후 KOSA-18 의 5 가지 모든 항목 및 총점이 술 전에 비해 통계적으로 유의 하게 감소하여 삶의 질이 명확하게 개선됨을 확인할 수는 있 었지만, 수술 전후 수면다원검사 결과가 없어 수면호흡장애 의 심각도 또는 개선 정도와 삶의 질 변화와의 관련성을 확 인할 수는 없었다. 따라서, 이번 연구를 계획하게 되었으며, 폐 쇄성수면무호흡증의 호전과 더불어 삶의 질이 통계적으로 유 의하게 개선되는 것을 객관적으로 증명할 수 있었다.

Mitchell과 Kelly)는 총 61명(43명의 폐쇄성수면무호흡증 환자 및 18 명의 경도 수면호흡장애 환자)의 소아들을 대상으 로 편도 및 아데노이드 절제술 전후 삶의 질(OSA-18)을 평 가한 결과 수면호흡장애의 심각도와 상관없이 술 후 삶의 질 (OSA-18의 모든 항목 및 총점)이 유의하게 호전된다는 것을 발표하였다. 본 연구에서도 폐쇄성수면무호흡증의 심각도와 상관없이 편도 및 아데노이드 절제술 후 삶의 질이 크게 호전 됨을 확인할 수 있었다.

Baldassari 등 ${ }^{14)}$ 은 수면호흡장애가 있는 소아들을 대상으 로 OSA-18을 이용하여 편도 및 아데노이드 절제술 전후 삶의 질을 평가한 7편(총 369명)의 논문을 분석한 결과 술 후 단기 (short-term, 6개월 미만, 5편)적으로나 장기(long-term, 6개 월 이상, 2편)적으로 삶의 질(OSA-18의 5가지 항목 및 이를 모두 합한 총점)이 유의하게 호전됨을 보고하였다. 이번 연구 에서는 2 차 수면다원검사 및 설문조사가 수술 3 개월 후 이루 어져 단기 결과이며, 향후 장기적인 추적관찰이 필요하리라 생각된다.

한편, 본 연구에서 수술 성공 기준을 술 후 폐쇄성 무호흡저호흡 지수(obstructive $\mathrm{AHI}$ <1로 정의한 경우 성공률은 95\%(19/20)로 조사되었다. 하지만, 이러한 기준에 포함되지 않은 1 명의 환자 역시 폐쇄성 무호흡-저호흡 지수가 술 전 25.7 에서 술 후 1.7 로 큰 폭으로 감소하였기 때문에 거의 정상 에 가까운 상태로 생각된다. 본 환자의 KOSA-18 총점은 술 전 61에서 술 후 22로 감소한 것으로 나타났는데, 성공 기준에 포 함된 환자들에 비해 별다른 차이점은 발견할 수 없었다.

이번 연구의 큰 장점은 수술 전후의 수면다원검사 결과 비 교를 통해 객관적으로 폐쇄성수면무호흡증이 호전됨에 따라 삶의 질이 좋아지는 것을 확인할 수 있었다는 점이다. 또한, 수 면다원검사 지표(예를 들어, 무호흡-저호흡 지수)와 $\mathrm{KOSA}-$
18(각 항목 점수 및 총점수) 간의 수술 전후 비교를 통해 여러 가지 정보들을 알 수 있었다는 점이다. 하지만 본 연구에도 몇 가지 제한점이 있는데, 첫째는 대조군이 없다는 점이고, 둘째 는 대상자의 수가 상대적으로 적은 점이다. 좀 더 많은 소아 환자들을 대상으로 실험군과 대조군으로 나누어 다음 연구 를 시행한다면 좀 더 신뢰도가 높은 결과를 얻을 수 있을 것 으로 사료된다.

\section{REFERENCES}

1) Marcus CL. Sleep-disordered breathing in children. Am J Respir Crit Care Med 2001;164(1):16-30.

2) Li Z, Celestin J, Lockey RF. Pediatric sleep apnea syndrome: an update. J Allergy Clin Immunol Pract 2016;4(5):852-61.

3) Ali NJ, Pitson DJ, Stradling JR. Snoring, sleep disturbance, and behaviour in 4-5 year olds. Arch Dis Child 1993;68(3):360-6.

4) Brunetti L, Rana S, Lospalluti ML, Pietrafesa A, Francavilla R, Fanelli M, et al. Prevalence of obstructive sleep apnea syndrome in a cohort of 1,207 children of southern Italy. Chest 2001;120(6): 1930-5.

5) American Academy of Sleep Medicine. International classification of sleep disorders. 3rd ed. Darien, IL: American Academy of Sleep Medicine; 2014

6) Capdevila OS1, Kheirandish-Gozal L, Dayyat E, Gozal D. Pediatric obstructive sleep apnea: complications, management, and long-term outcomes. Proc Am Thorac Soc 2008;5(2):274-82.

7) Franco RA Jr, Rosenfeld RM, Rao M. First place--resident clinical science award 1999. Quality of life for children with obstructive sleep apnea. Otolaryngol Head Neck Surg 2000;123(1 Pt 1):9-16.

8) Mitchell RB, Kelly J, Call E, Yao N. Long-term changes in quality of life after surgery for pediatric obstructive sleep apnea. Arch Otolaryngol Head Neck Surg 2004;130(4):409-12.

9) Mitchell RB, Kelly J. Quality of life after adenotonsillectomy for SDB in children. Otolaryngol Head Neck Surg 2005;133(4):569-72.

10) Choi JH, Lee SH, Lee HM, Lee JK, Kwon SY, Shin C, et al. Correlation between quality of life and personality, behavior problem in children with sleep disordered breathing. Korean J Otolaryngol-Head Neck Surg 2005;48(10):1235-41.

11) Lim HW, Lee SH, Lee HM, Choi JH, Kwon SY, Shin C, et al. Correlation between quality of life and indices of polysomnography in children with obstructive sleep apnea syndrome. Korean J Otolaryngol-Head Neck Surg 2006;49(1):35-40.

12) Cho WJ, Lee SH, Choi J, Cho WS, Lee SH, Lee HM, et al. Changes in quality of life after adenotonsillectomy in children with sleep disordered breathing. Korean J Otolaryngol-Head Neck Surg 2006; 49(4):402-6.

13) Goldstein NA, Fatima M, Campbell TF, Rosenfeld RM. Child behavior and quality of life before and after tonsillectomy and adenoidectomy. Arch Otolaryngol Head Neck Surg 2002;128(7):770-5.

14) Baldassari CM, Mitchell RB, Schubert C, Rudnick EF. Pediatric obstructive sleep apnea and quality of life: a meta-analysis. Otolaryngol Head Neck Surg 2008;138(3):265-73. 